\title{
Preparation of Ternary Cathode Materials from Spent Lithium Batteries at Low Temperature
}

\author{
Jingjing He ${ }^{1}$, Zitong $\mathrm{Fei}^{1}$, Qi Meng ${ }^{1,{ }^{*}, \text { Peng Dong }}{ }^{1 *}$, Yingjie Zhang $^{1{ }^{*}}$, Qingxiang $\mathrm{Li}^{2}$ \\ ${ }^{1}$ Faculty of Metallurgy and Energy Engineering, National and Local Joint Engineering Laboratory for \\ Lithium-ion Batteries and Materials Preparation Technology, Kunming University of Science and \\ Technology, Kunming, 650093, China. \\ ${ }^{2}$ Shenzhen Zhongjin Lingnan Technology Co., Ltd., Shenzhen 518118, China. \\ *E-mail: mengqi315117@126.com
}

doi: $10.20964 / 2021.03 .38$

Received: 29 October 2020 / Accepted: 17 December 2020 / Published: 31 January 2021

\begin{abstract}
In order to avoid the shortcomings of long process and low recovery rate during the existing recycling of spent lithium-ion batteries. A novel process was developed for regeneration of spent $\mathrm{LiNi}_{0.5} \mathrm{Co}_{0.2} \mathrm{Mn}_{0.3} \mathrm{O}_{2}$ cathode in $\mathrm{Li}^{+}$molten salt solution at low temperature under atmospheric pressure. Based on regeneration at low temperature, the initial discharge capacity of the regenerated cathode material is $169.1 \mathrm{mAh} \cdot \mathrm{g}^{-1}$, and the capacity retention rate is $89.36 \%$ after 200 cycles. The regenerated NCM523 sample changed from $165.9 \mathrm{mAh} \cdot \mathrm{g}^{-1}$ at $0.1 \mathrm{C}$ to $137.35 \mathrm{mAh} \cdot \mathrm{g}^{-1}$ at $5 \mathrm{C}$ and the rate capacity measured at the current density of $0.1 \mathrm{C}$ is almost as the same as the original capacity. The original composition and crystal structure of NCM523 cathode are regenerated, which makes the capacity, cycle stability and rate capability reached the level of original material.
\end{abstract}

Keywords: Ternary materials; Lithium ion battery; Regeneration; Low temperature lithium addition; $\mathrm{LiNi}_{0.5} \mathrm{Co}_{0.2} \mathrm{Mn}_{0.3} \mathrm{O}_{2}$ cathode material

\section{FULL TEXT}

(C) 2021 The Authors. Published by ESG (www.electrochemsci.org ). This article is an open access article distributed under the terms and conditions of the Creative Commons Attribution license (http://creativecommons.org/licenses/by/4.0/). 